\title{
Trends in Demographics and Surgical Treatment of Weapon- Related Limb Injuries Over Two Decades in a Resource-Scarce Setting
}

\author{
Måns Muhrbeck ${ }^{1,2}$ (1) $\cdot$ Kaspar Holmgren $^{3} \cdot$ Zaher Osman $^{4} \cdot$ Johan von Schreeb $^{5} \cdot$ \\ Andreas Wladis $^{2,6}$ - Peter Andersson ${ }^{1,7}$
}

Published online: 12 August 2019

(C) The Author(s) 2019

\begin{abstract}
Background In the past decades, surgical management of limb injuries in high-resource settings has improved. The possibility of limb salvage has increased. It is not known whether similar changes have transpired in resource-scarce conflict settings.

Methods Retrospective cohort study using routinely collected patient data from the International Committee of the Red Cross hospitals in Pakistan was conducted. Consecutive data from 2009 to 2012 (535 patients) and randomly selected data from 1992 to 1995 (463 patients) were used. Only patients with weapon-related limb injuries were included. Differences in surgical procedures were assessed with logistic regression to adjust for confounding factors. Results Less injuries were related to mines in 2009-2012 than in 1992-1995 (3.7\% vs. $20.3 \%, p<0.0001)$, but injuries from bombs, shells and fragments were more frequent $(38.5 \%$ vs. $19.4 \%, p<0.0001)$ as were injuries with only a small degree of tissue damage $(42.0 \%$ vs. $31.1 \%, p=0.0004)$. In the logistic regression, the time period did not affect the risk of amputation, debridement, length of hospital stay or in-hospital mortality. The use of external fixation (OR 0.56, 95\% CI 0.33-0.96, $p=0.04$ ), split skin grafts (OR $0.31,95 \%$ CI $0.21-0.45, p<0.0001$ ) and blood transfusion (OR 0.43, 95\% CI 0.28-0.66, $p=0.0001$ ) was less frequent in 2009-2012.

Conclusion In this resource-scarce conflict setting, the risk of amputation appears unchanged over time, while the use of external fixation and split skin grafts was less common in 2009-2012 than in 1992-1995. These results contrast with the improved limb salvage results seen in high-resource settings. It likely reflects the challenges of providing advanced limb-preserving techniques in a resource-scarce setting.
\end{abstract}

Previous presentation of study: Preliminary results were presented orally at the Swedish Surgical Society, Surgical Society Annual Meeting, 21-25 August 2017, in Jönköping, Sweden, and an abstract has been presented orally at the $20^{\text {th }}$ European Congress of Trauma \& Emergency Surgery, 5-7 May 2019, in Prague, Czech Republic.

Electronic supplementary material The online version of this article (https://doi.org/10.1007/s00268-019-05110-y) contains supplementary material, which is available to authorized users.

Måns Muhrbeck

mans.muhrbeck@liu.se

1 Department of Surgery, and Department of Clinical and Experimental Medicine, Linköping University,

60379 Norrköping, Sweden

\section{Introduction}

Limb injuries account for a majority (50-75\%) of survivable injuries in conflicts. Between 25 and $33 \%$ are combined with fractures, and the lower limbs are most commonly affected [1-5]. Amputation rates following major limb injuries in conflicts range between 7 and 19\% [6-8]. In 2015, it was estimated that approximately 1.2

2 Center for Teaching and Research in Disaster Medicine and Traumatology, University Hospital, Linköping, Sweden

3 Faculty of Health Sciences, University of Southern Denmark, Odense, Denmark 
million people were amputated due to injuries globally [9]. Incidences vary considerably, ranging from 1.2 in Canada and up to 371 per 100,000 population in the Middle East and North Africa [9-11]. Over the last decades advancements in orthopaedic, plastic and vascular surgical techniques have made many severely injured limbs salvageable in high-resource settings [12, 13]. Data from the United States Healthcare Cost and Utilization Project showed a decrease in the amputation rates due to trauma by $51.5 \%$ between 1988 and 1996 [14]. Among Medicare patients, in the USA, a $45 \%$ decrease of lower limb amputations for all causes was observed between 1996 and 2011 [15]. It remains unclear whether similar improvements have been achieved in conflict-affected low- and middle-resource settings where constraints, such as logistical challenges and security issues, may limit implementations of advances in treatment practices [16]. These constraints in the delivery of and access to surgical care emphasize the importance of understanding what surgical resources are needed in a given context. Identifying trends in surgical treatment of limb injuries could therefore have implications on how surgical care is delivered in resource-scarce conflict settings. To fill this knowledge gap, we analysed routinely collected surgical hospital data from patients with weaponrelated limb injuries treated at two of the International Committee of the Red Cross (ICRC) field hospitals, in Pakistan, during 1992-1995 and 2009-2012. The ICRC is a humanitarian organization providing medical assistance to victims of war and other situations of violence by independently running or otherwise supporting hospitals with limited resources where with the ICRC support surgery can be provided free for the weapon-wounded. The ICRC has since its first field mission in 1875 provided specialized surgical care to limb injured in conflicts [17].

\section{Aim of study}

To investigate trends in demographics and surgical practices of weapon-related limb injuries in a resource-scarce setting between 1992-1995 and 2009-2012 with a particular focus on amputation rates.

4 International Committee of the Red Cross, Geneva, Switzerland

5 Department of Public Health Sciences, Karolinska Institutet, Stockholm, Sweden

6 Department of Clinical and Experimental Medicine, Linköping University, Linköping, Sweden

7 International Medical Programme, Center for Teaching and Research in Disaster Medicine and Traumatology, University Hospital, Linköping, Sweden

\section{Patients and setting}

Patients' injuries for both time periods were mainly caused during the ongoing armed conflict that was characterized by the use of explosives, grenades, attacks by gunmen and aerial bombings on both sides of the Pakistani-Afghanistan border [18]. In response to the conflict in Afghanistan, the ICRC opened its first hospital 60 kilometres from the Afghanistan border in Peshawar, north-western Pakistan, in 1981. This was followed by opening of another hospital in Quetta, 80 kilometres from the border and $840 \mathrm{~km}$ south of Peshawar, in 1983. Both hospitals closed in the 1990s, but due to intensification of the conflicts in the border area, the Peshawar hospital was reopened in 2009 and remained in operation until $2012[19,20]$. Local citizens with weaponrelated injuries were also treated at the hospitals and are included in the study. Those seeking care were not asked whether they were civilians or combatants. Both hospitals had access to rehabilitation centres for training and prosthesis fitting [19, 21]. Care at these ICRC's hospitals was free of charge.

\section{Methods}

This retrospective cohort study used routinely collected patient data. Inclusion criteria were all patients admitted to the ICRC's hospital in Quetta or Peshawar, during 2009-2012 and 1992-1995, respectively, with weapon-related penetrating injuries to the limbs. Exclusion criteria were if patients had: significant injury to other sites than limbs requiring medical attention other than a basic dressing, injuries older than seven days, traumatic amputations including partial or total avulsion of the limb or missing data on confounders (see statistical methods). Patients with the most significant injury located distal to the metacarpophalangeal joints of the hand or mid-tarsal joints of the foot were excluded because these commonly only required simpler surgical treatment, such as a single debridement (DBR) or change of dressing (COD). In case of multiple admissions, only the first one was included. Comparisons were made between the incidence of all of the following variables, as recorded for each of the two time periods: in-hospital amputations, external fixation, split skin graft (SSG), DBR or COD under general anaesthesia three times or more, blood transfusion, 21 days or more of hospital stay (LOS) and in-hospital mortality. DBR and COD done in the operation theatre were merged into one group in the analysis as both procedures required general anaesthesia.

The ICRC has since 1991 routinely used the Red Cross Wound Classification (RCWC) to categorize penetrating injuries. RCWC is based on entry and exit diameters of the 
wound, cavity, fracture severity, vital vessel injury and presence of metal fragments in the wound. For limb injuries, vital vessel injury is defined as injuries to vessels proximal to the knee or elbow. Depending on type (soft tissue, fracture, vital structure and vital structure with fracture) and grade (1-3), a penetrating wound is categorized into twelve different categories [22-24]. The grade directly translates into degree of tissue damage at injury [24]. Grade 1 was assigned small, grade 2 medium, and grade 3 extensive tissue damage. In this study, the grade for the main treated limb wound was registered for all patients to adjust for differences in degree of tissue damage between time periods. The presence of a second penetrating limb wound, other than one merely requiring basic dressing deemed as not affecting outcome, was dichotomously registered as existing or not.

Data for the 2009-2012 time period were collected from an anonymized database containing routinely collected data from all 3028 patients treated at the ICRC's hospital in Peshawar between 18 February 2009 and 9 May 2012. The data were entered, at the time, into an Excel database mainly by one of the authors ( $\mathrm{ZO}$ ), whose job primarily entailed maintaining the database at the ICRC's hospital in Peshawar.

Data from 1992 to 1995 were collected from paperbased patient files by two of the authors (MM and $\mathrm{KH}$ ) from ICRC's archives in Satigny, Switzerland, between October and November 2016. Approximately 8000 handwritten files are stored in these archives and include files from both ICRC's hospitals in Quetta and Peshawar. Files are stored in boxes in no particular order with 7-10 files in each box. Boxes that contained files from 1992 to 1995 were randomly selected from listings on Excel spreadsheets. Randomization was achieved by using built-in random functions in the Python programming language [25]. To ensure even distribution, the first 6 files from each box that met our inclusion criteria were selected. Considering the available data from the 2009-2012 database, there will be a minimum detectable difference of $6 \%$ at $80 \%$ statistical power between the time periods.

\section{Statistical methods}

Statistical analysis was made using SPSS Statistics software version 25 (IBM Corporation, Armonk, NY, USA). To adjust for the impact of patients who required extensive resources, the number of in-hospital amputations, external fixations, SSG and blood transfusions are given as proportion of patient numbers, i.e. if a patient had several inhospital amputations, SSG, external fixations or blood transfusions, only one was counted.
Descriptive comparisons between the 2009-2012 and 1992-1995 periods were analysed using Fisher's exact test or Chi-square for categorical variables and Mann-Whitney $U$-test for continuous variables. Values are given as mean with standard deviation (SD) and median with interquartile range (IQR) where appropriate. To compare in-hospital amputations, use of external fixation, SSG and $\geq 3$ DBR/ COD, blood transfusion, $\geq 21$ days LOS and in-hospital mortality, binary logistic regression analysis was performed to adjust for confounding factors between time periods. Gender, age $(<16,16-49$ and $>49$ yrs.), time since injury $(<24,24-48$ and $>48 \mathrm{~h})$, mean arterial pressure $(<65$ and $\geq 65 \mathrm{mmHg}$ ) on admission, degree of tissue damage (small, medium and extensive), second penetrating wound (yes and no), vital vessel injury (yes and no) and time period (1992-1995 and 2009-2012) were identified as confounding factors as they had been shown to have significant influence in the univariate analysis or previously had been reported to influence the risk of outcomes, especially for in-hospital amputations [26, 27]. Forward Wald was used to calculate a final regression model. Differences in frequency of procedures between time periods are presented as odds ratios (OR) with 95\% confidence intervals. $P$-values (two-tailed) less than 0.05 were considered significant for both the univariate and logistic regression analyses.

\section{Results}

A total of 535 patients treated in 2009-2012 and 463 treated in 1992-1995 were included in the final analysis (Fig. 1). There was a larger proportion of women than men and more patients under 16 years and over 49 years in 2009-2012 compared to 1992-1995 ( $p<0.01$ for both) (Table 1). More patients were treated for injuries related to bombs, shells and fragments $(p<0.0001)$ and fewer related to anti-personal mines (APM) in 2009-2012 than in 1992-1995 ( $p<0.0001)$ (Table 2). There were no differences in time from injury to arrival at hospital (median $24 \mathrm{~h}$, IQR 64, in 2009-2012 and $24 \mathrm{~h}$, IQR 32, in 1992-1995).

Comparisons of injury patterns between the time periods are shown in Table 3. Large wounds with comminute fractures $(p<0.0001)$ were less frequent in 2009-2012 than 1992-1995, while simple wounds with or without fracture and fractures with vascular injuries were more frequent ( $p<0.01$ for both). Likewise, injuries resulting in a small degree of tissue damage were more frequent in $2009-2012(p=0.0004)$. A majority of injuries were to the lower limbs for both time periods $(61.9 \%$, in 2009-2012 and $64.4 \%$, in $1992-1995, p=0.42$ ). There was no difference in the presence of a second penetrating limb wound 


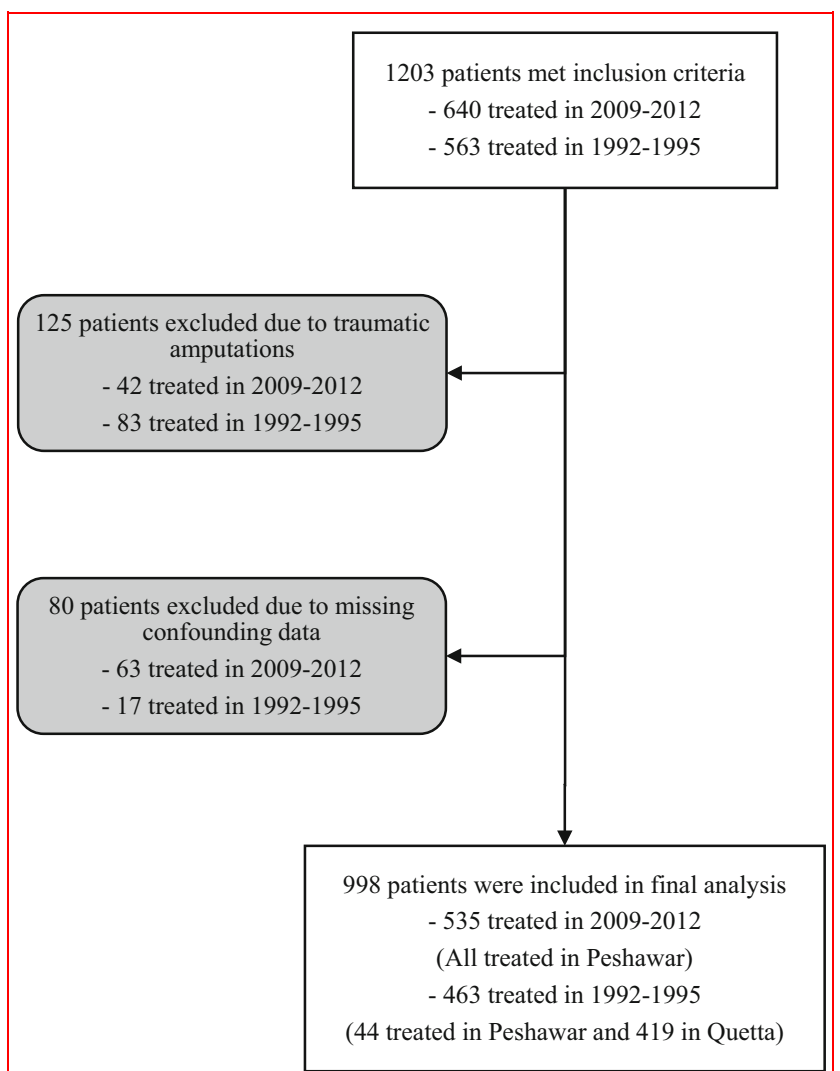

Fig. 1 Flow chart of patient inclusion in the study

$(p=0.08)$. The relationship between time period and surgical procedures, LOS and in-hospital mortality is shown in Table 4. The univariate analysis revealed that in 2009-2012 patients had fewer external fixations $(p=0.008), \quad$ SSG $\quad(p<0.0001), \quad$ DBR/CODs $\geq 3$ $(p=0.02)$, blood transfusions $(p<0.0001)$ and shorter LOS $(p=0.007)$ than in 1992-1995, but the risk of inhospital amputations and mortality did not differ between the time periods. When adjusting for confounders by logistic regression, the time period did not prove to be related to the risk of in-hospital amputations, DBR/
Table 2 Mechanism of injury for patients treated for weapon-related limb injuries at ICRC's hospitals in Quetta and Peshawar, Pakistan, 1992-1995 and 2009-2012

\begin{tabular}{lllc}
\hline Mechanism & $\begin{array}{l}1992-1995 \\
\text { Total }=463 \\
n(\% \text { of total })\end{array}$ & $\begin{array}{l}2009-2012 \\
\text { Total }=535 \\
n(\% \text { of total })\end{array}$ & $\begin{array}{l}\text { Univariate } \\
\text { analysis } \\
P \text { value }\end{array}$ \\
\hline Anti-personnel mine & $94(20.3)$ & $20(3.7)$ & $<0.0001$ \\
Bomb, shell, fragment & $90(19.4)$ & $206(38.5)$ & $<0.0001$ \\
Gunshot & $273(59.0)$ & $306(57.2)$ & 0.57 \\
Other & $6(1.3)$ & $3(0.6)$ & 0.22 \\
\hline
\end{tabular}

CODs $\geq 3, \quad$ LOS $\geq 21$ days or in-hospital mortality. However, in the final regression model, the use of external fixations (OR 0.56, 95\% CI 0.33-0.96, $p=0.04$ ), SSG (OR $0.31,95 \%$ CI $0.21-0.45, p<0.0001)$ and blood transfusions (OR 0.43, 95\% CI 0.28-0.66, $p=0.0001$ ) was still less frequent in 2009-2012 than in 1992-1995. Complete regression models are shown in Supplement Tables 1-7.

\section{Discussion}

This is to our knowledge the first study focusing on trends in surgical treatment practices for limb injuries over a time period of two decades in a resource-scarce conflict setting. After adjusting for confounders, particularly the degree of tissue damage, no difference in amputation-risk could be detected between 1992-1995 and 2009-2012, nor were there any statistically significant differences in the use of DBR/COD, LOS or in-hospital mortality. However, the use of external fixation, SSG and blood transfusion had declined in 2009-2012. There are several plausible explanations for the observed differences in surgical procedures between the two time periods. Surgeons deployed by the ICRC during both time periods were predominantly specialist general surgeons from high-resource countries (personal communication with the ICRC's health unit). Their familiarity with basic orthopaedic, plastic and

Table 1 Gender and age distribution for patients treated for weapon-related limb injuries at ICRC's hospitals in Quetta and Peshawar, Pakistan, 1992-1995 and 2009-2012

\begin{tabular}{|c|c|c|c|c|c|}
\hline Age and Gender & $\begin{array}{l}1992-1995 \\
\text { Total }=463 \\
n(\%)\end{array}$ & Mean (SD) & $\begin{array}{l}2009-2012 \\
\text { Total }=535 \\
n(\%)\end{array}$ & Mean (SD) & $\begin{array}{l}\text { Univariate } \\
\text { analysis } \\
P \text { value }\end{array}$ \\
\hline Gender & & & & & $<0.0001$ \\
\hline Male & $449(97.0)$ & & $466(87.1)$ & & \\
\hline Female & $14(3.0)$ & & 69 (12.9) & & \\
\hline Age & & $26.2(10.8)$ & & $27.2(13.9)$ & 0.22 \\
\hline$<16$ years & $52(11.2)$ & & $92(17.2)$ & & 0.007 \\
\hline $16-49$ & $387(83.6)$ & & $388(72.5)$ & & $<0.0001$ \\
\hline$>49$ & $24(5.2)$ & & $55(10.3)$ & & 0.003 \\
\hline
\end{tabular}


Table 3 Injury patterns for patients treated for weapon-related limb injuries at ICRC's hospitals in Quetta and Peshawar, Pakistan, 1992-1995 and 2009-2012

\begin{tabular}{|c|c|c|c|}
\hline Injury pattern & $\begin{array}{l}1992-1995 \\
\text { Total }=463 \\
n(\% \text { of total })\end{array}$ & $\begin{array}{l}2009-2012 \\
\text { Total }=535 \\
n(\% \text { of total })\end{array}$ & $\begin{array}{l}\text { Univariate analysis } \\
P \text { value }\end{array}$ \\
\hline \multicolumn{4}{|l|}{ Type of injury } \\
\hline Simple wound ${ }^{\mathrm{a}} \pm$ fracture & $188(40.6)$ & $267(49.9)$ & 0.003 \\
\hline Medium wound $^{\mathrm{b}}+$ com. fracture $^{\mathrm{d}}$ & $151(32.6)$ & $168(31.4)$ & 0.68 \\
\hline Large wound ${ }^{\mathrm{c}}$ - fracture & $15(3.2)$ & $16(3.0)$ & 0.82 \\
\hline Large wound ${ }^{\mathrm{c}}+$ com. fracture ${ }^{\mathrm{d}}$ & $84(18.2)$ & $36(6.7)$ & $<0.0001$ \\
\hline Any fracture + vascular injury & $15(3.2)$ & $37(6.9)$ & 0.009 \\
\hline Vascular injury - fracture & $10(2.2)$ & $11(2.1)$ & 0.91 \\
\hline \multicolumn{4}{|l|}{ Tissue damage } \\
\hline Small & $144(31.1)$ & $225(42.0)$ & 0.0004 \\
\hline Medium & $210(45.4)$ & $238(44.5)$ & 0.78 \\
\hline Extensive & $109(23.5)$ & $72(13.5)$ & $<0.0001$ \\
\hline \multicolumn{4}{|l|}{ Location of injury } \\
\hline Upper limb & $97(20.9)$ & $132(24.7)$ & 0.16 \\
\hline Lower limb & $298(64.4)$ & $331(61.9)$ & 0.42 \\
\hline Upper and lower limbs & $68(14.7)$ & $72(13.4)$ & 0.58 \\
\hline Second wound & & & 0.08 \\
\hline No & $359(77.5)$ & $439(82.1)$ & \\
\hline Yes & $104(22.5)$ & 96 (17.9) & \\
\hline
\end{tabular}

\footnotetext{
${ }^{a}$ Simple wound = Entry and exit site less than $10 \mathrm{~cm}$ in total and no wound cavity

${ }^{\mathrm{b}}$ Medium wound = Entry and exit site less than $10 \mathrm{~cm}$ in total and wound cavity

${ }^{\mathrm{c}}$ Large wound $=$ Entry and exit site more than $10 \mathrm{~cm}$ in total and wound cavity

${ }^{\mathrm{d}}$ Com. Fracture $=$ Comminute fracture
}

vascular surgery may have varied. This is especially true for the later time period as current trends in surgical training in high-resource countries have favoured subspecialization with specific rather than general skill sets [28]. In a recent survey among ICRC health care staff on selfperceived training needs, $31 \%$ requested additional training in fracture surgery, $20 \%$ in reconstructive surgery and 19\% in vascular surgery [29]. This together with our findings calls for adapting pre-deployment preparation and international team composition to better address context-varying injuries.

The decreased use of external fixation in 2009-2012 could also be due to a more restrictive use of this technique based on changes in ICRC's treatment practices between the time periods (personal communication with former ICRC coordinator of surgical programmes Åsa Molde). Fewer blood transfusions in 2009-2012 may be an effect of less severe limb injuries (Table 3 ).

The frequency of amputations in this study remained the same over time, whereas it has gradually decreased in civilian high-resource settings $[14,15]$. This discrepancy in treatment routines between high- and low-resource settings is not unusual and also occurs in other types of trauma [16]. Availability of equipment, medicines, as well as familiarity with reconstructive techniques including flaps will affect how the surgeons in the field choose to deal with complex limb injuries.

In 2009-2012, a larger proportion of the admitted patients were women and children, and fewer were treated for extensive soft tissue injuries and fracture commination than in 1992-1995 (Tables 1 and 3). These differences in demographics and injury patterns might be explained by an increasingly indiscriminate nature of warfare over time resulting in more patients admitted with injuries from explosives, mortars, aerial bombings and fewer from APM (Table 2). Fewer limb injuries from APM could potentially be attributed to the implementation of the Ottawa treaty between the time periods. The treaty was endorsed by several fighting parties in the region [30]. It bans the use, stockpiling, production and transfer of APM and promotes their destruction [31]. For both time periods, a very low mortality for admitted patients in spite of severe limb injuries was observed (Table 4). 
Table 4 Relationship between time period and surgical procedures, hospital stay and mortality for patients treated for weapon-related limb injuries at ICRC's hospitals in Quetta and Peshawar, Pakistan, 1992-1995 and 2009-2012

\begin{tabular}{|c|c|c|c|c|c|c|c|}
\hline \multirow[t]{2}{*}{ Time period } & \multicolumn{3}{|c|}{$\begin{array}{l}\text { Univariate analysis } \\
\text { Total }=998\end{array}$} & \multicolumn{4}{|c|}{$\begin{array}{l}\text { Logistic regression analysis } \\
\text { Total }=998\end{array}$} \\
\hline & $\begin{array}{l}1992-1995 \\
\text { Total }=463 \\
n(\%)\end{array}$ & $\begin{array}{l}2009-2012 \\
\text { Total }=535 \\
n(\%)\end{array}$ & $P$ value & $\begin{array}{l}\text { All confounders }{ }^{\mathrm{a}} \\
1=1992-1995 \\
\text { Odds ratio }(95 \% \mathrm{CI}) \\
\text { for } 2009-2012\end{array}$ & $P$ value & $\begin{array}{l}\text { Final model } \\
1=1992-1995 \\
\text { Odds ratio }(95 \% \mathrm{CI}) \\
\text { for } 2009-2012\end{array}$ & $P$ value \\
\hline In-hospital amputation & & & 0.20 & & & & \\
\hline No & $417(90.1)$ & $494(92.3)$ & & 1 & & 1 & \\
\hline Yes & $46(9.9)$ & $41(7.7)$ & & $1.20(0.69-2.09)$ & 0.51 & $1.12(0.66-1.91)$ & 0.67 \\
\hline External fixation & & & 0.008 & & & & \\
\hline No & $422(91.1)$ & $510(95.3)$ & & 1 & & 1 & \\
\hline Yes & $41(8.9)$ & $25(4.7)$ & & $0.63(0.36-1.08)$ & 0.09 & $0.56(0.33-0.96)$ & 0.04 \\
\hline Split skin graft & & & $<0.0001$ & & & & \\
\hline No & $330(71.3)$ & $478(89.3)$ & & 1 & & 1 & \\
\hline Yes & $133(28.7)$ & $57(10.7)$ & & $0.31(0.21-0.46)$ & $<0.0001$ & $0.31(0.21-0.45)$ & $<0.0001$ \\
\hline $\begin{array}{l}\text { Debridement/change of } \\
\text { dressing }\end{array}$ & & & 0.02 & & & & \\
\hline $0-2$ & $310(67.0)$ & $393(73.5)$ & & 1 & & 1 & \\
\hline$\geq 3$ & $153(33.0)$ & $142(26.5)$ & & $0.89(0.65-1.22)$ & 0.48 & $0.89(0.66-1.20)$ & 0.46 \\
\hline Blood transfusion & & & $<0.0001$ & & & & \\
\hline No & $371(80.1)$ & 485 (90.7) & & 1 & & 1 & \\
\hline Yes & $92(19.9)$ & $50(9.3)$ & & $0.41(0.27-0.64)$ & $<0.0001$ & $0.43(0.28-0.66)$ & 0.0001 \\
\hline Length of hospital stay & & & 0.007 & & & & \\
\hline$<21$ days & $228(49.2)$ & $309(57.8)$ & & 1 & & 1 & \\
\hline$\geq 21$ days & $235(50.8)$ & $226(42.2)$ & & $0.82(0.62-1.10)$ & 0.18 & $0.87(0.66-1.14)$ & 0.31 \\
\hline In-hospital mortality & & & 0.18 & & & & \\
\hline No & 458 (98.9) & $533(99.6)$ & & 1 & & 1 & \\
\hline Yes & $5(1.1)$ & $2(0.4)$ & & $0.47(0.07-2.96)$ & 0.42 & $0.32(0.06-1.67)$ & 0.18 \\
\hline
\end{tabular}

${ }^{a}$ Gender, age, time since injury, mean arterial pressure, degree of tissue damage, presence of second penetrating wound and vital vessel injury were also included as confounders in the logistic regression analysis, but not reported in this table. For full logistic regression analysis see Table 5-11 in Supplement

\section{Limitations}

This study has limitations. Considering the difficulties in reaching the hospitals for various reasons and the late presentations, it can be safely assumed that many severely injured patients died before reaching the respective hospitals. This should not affect the surgical treatment given to admitted patients with limb injuries during both time periods. In this study, we included patients from two different ICRC's hospitals, which also could lead to patient selection and treatment bias. Previously published data from both hospitals, however, demonstrate that patients' injury patterns were similar and both hospitals adhered to the ICRC's treatment protocols [24].

This study only includes patients treated at ICRC's hospitals in Pakistan. Therefore, the external validity of our findings may be limited. The patients were nonetheless treated according to ICRC's treatment protocols that are generally accepted and similar to protocols followed by other humanitarian organizations and surgical care providers in conflicts [32-34]. Finally, the study is retrospective and consequently has inherent weaknesses that come with this study design, such as general selection bias and missing data. To mitigate selection bias, we used random sampling for the 1992-1995 time period and included all patients that meet the inclusion criteria for 2009-2012. Patients that were excluded due to missing confounding data did not differ significantly from analysed patients in terms of in-hospital amputations or other surgical procedures.

\section{Conclusions}

In this resource-scarce conflict setting, almost all admitted patients with weapon-related injuries survived. While the use of external fixation and split skin graft was less 
common in 2009-2012 than in 1992-1995, the risk of amputation remained unchanged over time. These results contrast with the improved limb salvage results seen during the same time period in high-resource settings. It likely reflects the significant challenges of providing limb-preserving techniques in a resource-scarce conflict setting. Adjusting pre-deployment preparation and team composition could be one strategy to mitigate some of these challenges. Further investigation is needed to assess whether such strategies have the desired effect of improving surgical care in resource-scarce conflict settings.

Acknowledgements Open access funding provided by Linköping University. We thank former ICRC coordinator of surgical programmes Åsa Molde and former ICRC surgeon Günter Wimhöfer for providing background information on ICRC's activities in Afghanistan and Pakistan and Lars Valter, Forum Östergötland, Linköping University, Sweden, for statistical advice. Funding was provided by Sigurd and Elsa Goljes Memorial Foundation and ALF grants, Region Östergötland, Sweden.

Author contribution This study was conceived by MM and PA. The study design was made by MM, KH, JvS and PA. Data were collected by $\mathrm{KH}, \mathrm{MM}$ and $\mathrm{ZO}$ and analysed by $\mathrm{KH}, \mathrm{MM}$ and $\mathrm{PA}$. Interpretation of the data was done by KH, MM, ZO, AW, JvS and PA. The first draft of the manuscript was made by MM and was critically revised by all authors.

Funding Sigurd and Elsa Goljes Memorial Foundation and ALF grants, Region Östergötland, Sweden (Grant Numbers LIO-799621, LA2016-0457).

\section{Compliance with ethical standards}

Conflict of interest The authors have no conflicts of interest to declare. ZO has a long-term contract, AW has had a long-term contracts, and PA intermittent short-term contract with the ICRC.

Ethical approval Exploration of data was approved by the Regional Ethical Review Board in Linköping, Sweden (Dnr. 2014/417-31, 2015/66-33, 2016/298-32).

Open Access This article is distributed under the terms of the Creative Commons Attribution 4.0 International License (http://crea tivecommons.org/licenses/by/4.0/), which permits unrestricted use, distribution, and reproduction in any medium, provided you give appropriate credit to the original author(s) and the source, provide a link to the Creative Commons license, and indicate if changes were made.

\section{References}

1. Cernak I, Savic J, Ignjatovic D et al (1999) Blast injury from explosive munitions. J Trauma 47:96-103

2. Hinsley DE, Rosell PA, Rowlands TK et al (2005) Penetrating missile injuries during asymmetric warfare in the 2003 Gulf conflict. BJS 92:637-642

3. Aboutanos MB, Baker SP (1997) Wartime civilian injuries: epidemiology and intervention strategies. J Trauma 43:719-726
4. Trouwborst A, Weber BK, Dufour D (1987) Medical statistics of battlefield casualties. Injury 18:96-99

5. Nerlander MP, Haweizy RM, Wahab MA et al (2019) Epidemiology of trauma patients from the Mosul Offensive, 2016-2017: results from a dedicated trauma center in Erbil, Iraqi Kurdistan. World J Surg 43:368-373. https://doi.org/10.1007/s00268-0184817-1

6. Islinger RB, Kuklo TR, McHale KA (2000) A review of orthopedic injuries in three recent U.S. military conflicts. Mil Med 165:463-465

7. Stansbury LG, Lalliss SJ, Branstetter JG et al (2008) Amputations in U.S. military personnel in the current conflicts in Afghanistan and Iraq. J Orthop Trauma 22:43-46

8. Andersson P, Muhrbeck M, Veen H et al (2018) Hospital workload for weapon-wounded females treated by the International Committee of the Red Cross: more work needed than for males. World J Surg 42:93-98. https://doi.org/10.1007/s00268$017-4160-y$

9. Vos T, Allen C, Arora M et al (2016) Global, regional, and national incidence, prevalence, and years lived with disability for 310 diseases and injuries, 1990-2015: a systematic analysis for the Global Burden of Disease Study 2015. Lancet 388:1545-1602

10. McDonald C (2017) Global incidence of major, non-fatal amputation due to traumatic causes. Dept. of Global Health, University of Washington. Washington. https://digital.lib. washington.edu/researchworkshandle/1773/40421?show=full Accessed 12 Jan 2019

11. Imam B, Miller WC, Finlayson HC et al (2017) Incidence of lower limb amputation in Canada. Can J Public Health 108:374-380

11. Lange RH (1989) Limb reconstruction versus amputation decision making in massive lower extremity trauma. Clin Orthop Relat Res 243:92-99

13. Saddawi-Konefka D, Kim HM, Chung KC (2008) A systematic review of outcomes and complications of reconstruction and amputation for type IIIB and IIIC fractures of the tibia. Plast Reconstr Surg 122:1796-1805

14. Dillingham TR, Pezzin LE, MacKenzie EJ (2002) Limb amputation and limb deficiency: epidemiology and recent trends in the United States. South Med J 95:875-883

15. Goodney PP, Tarulli M, Faerber AE et al (2015) Fifteen-year trends in lower limb amputation, revascularization, and preventive measures among medicare patients. JAMA Surg 150:84-86

16. Hofman K, Primack A, Keusch G et al (2005) Addressing the growing burden of trauma and injury in low- and middle-income countries. Am J Public Health 95:13-17

17. Palmieri D (2012) An Institution standing the test of time? IRRC 94:1273-1298

18. Arreguin-Toft I (2001) How the weak win wars: a theory of asymmetric conflict. Int Secur 26:93-128

19. Cuttat P, News bulletin, ICRC Hospital Peshawar (2009) International Committee of the Red Cross, Geneva. https://www.icrc. org/en/doc/assets/files/otherbulletin-icrc-march-09.pdf. Accessed 23 Nov 2018

20. Madrazo A, News bulletin, Pakistan: ICRC activities to continue on reduced scale (2012) International Committee of the Red Cross, Geneva. Available at: https://www.icrc.org/en/doc/resour ces/documents/news-release/2012/pakistan-news-2012-08-28. htm. Accessed 23 November, 2018

21. Maresca L, Casey-Maslen S (2000) The banning of anti-personnel landmines : the legal contribution of the International Committee of the Red Cross. Cambridge University Press, Cambridge, p 173

22. Coupland RM (1992) The Red Cross classification of war wounds: the E.X.C.F.V.M. scoring system. World J Surg 16:910-917. https://doi.org/10.1007/BF02066991 
23. Coupland RM, Brochure, The Red Cross wound classification (1993) International Committee of the Red Cross, Geneva, pp $1-15$

24. Giannou C, Baldan M, Red Cross wound score and classification (2009) In: War surgery: working with limited resources in armed conflict and other situations of violence, vol I, International Committee of the Red Cross, Geneva, pp 81-91, 109

25. Generate pseudo-random numbers, version 9.6 (2016) Computer programming language, Phyton Software Foundation. Available at:https://docs.python.org/2/library/. Accessed 23 Nov 2018

26. Davidovic LB, Cinara IS, Ille $\mathrm{T}$ et al (2005) Civil and war peripheral arterial trauma: review of risk factors associated with limb loss. Vascular 13:141-147

27. Groth AT, Kirk KL, Shawen SB, et al (2011) Surgery Foot in War Trauma. In: Lerner A, Soundry M (eds) Armed conflict injuries to the extremities: a treatment manual. Springer, Heidelberg, p 301

28. Stitzenberg KB, Sheldon GF (2005) Progressive specialization within general surgery: adding to the complexity of workforce planning. J Am Coll Surg 201:925-932

29. Haverkamp FJC, Veen H, Hoencamp R et al (2018) Prepared for mission? A survey of medical personnel training needs within the
International Committee of the Red Cross. World J Surg 42:3493-3500. https://doi.org/10.1007/s00268-018-4651-5

30. The International Campaign to Ban Landmines (2018) ICBLCMC, Geneva. https://www.icbl.org/en-gb/the-treaty/treaty-sta tus.aspx. Accessed 24 November, 2018

31. United Nation's Convention on the Prohibition of the use, stockpiling, production and transfer of anti-personnel mines and on their destruction (1997) APLC/MSP, United Nations New York. Available at: https://www.unog.ch. Accessed 3 December, 2018

32. Herard P, Boillot F (2012) Amputation in emergency situations: indications, techniques and Medecins Sans Frontieres France's experience in Haiti. Int Orthop 36:1979-1981

33. Mitkovic M, Bumbasirevic M, Grubor P et al (2013) Nature and results of treatment of war wounds caused by cluster bombs. Acta Chir Iugosl 60:41-47

34. Rew DA, Clasper J, Kerr G (2004) Surgical workload from an integrated UK field hospital during the 2003 Gulf conflict. JRAMC 150:99-106

Publisher's Note Springer Nature remains neutral with regard to jurisdictional claims in published maps and institutional affiliations. 